\title{
A Linearly Polarized Coaxial Feeding Dual Band Circular Microstrip Patch Antenna for WLAN Applications
}

\author{
Sheikh Dobir Hossain ${ }^{a^{*}}$, K. M. Abdus Sobahan ${ }^{\mathrm{b}}$, Md. Khalid Hossain ${ }^{\mathrm{c}}$, Md. Khalid Hossain \\ Jewel $^{\mathrm{d}}$, Rebeka Sultana ${ }^{\mathrm{e}}$, Md. Al Amin ${ }^{\mathrm{f}}$ \\ ${ }^{a}$ Dept. of Physics, Jessore University of Science and Technology, Jessore-7408, Bangladesh \\ ${ }^{b, d}$ Dept. of Applied Physics, Electronics \& Communication Engineering, Islamic University, Bangladesh \\ ${ }^{c}$ Institute of Electronics, Atomic Energy Research Establishment, Savar, Dhaka, Bangladesh \\ ${ }^{e}$ Department of Electrical and Electronic Engineering, Shizuoka University, Shizuoka, Japan \\ ${ }^{f}$ Dept. of CSE, Jessore University of Science and Technology, Jessore-7408, Bangladesh
}

\begin{abstract}
A dual band linearly polarized micro-strip antenna is designed and simulated to obtain electronic circuit miniaturization of an antenna in high speed wireless local area networks (IEEE 802.11a standard). The proposed antenna contains a substrate layer (FR-4 lossy) with a dielectric constant of 4.4 and there is a circular patch on the upper layer of the substrate. The coaxial probe feed is used to excite the desired antenna which reduces the spurious radiation and hence obtained good efficiency. It is shown that using cavity model $20 \%$ excess bandwidth can be achieved while maintaining the lower size of the antenna. An ' $\mathrm{E}$ ' shaped slot is introduced in the radiating patch to obtain dual band resonance frequency with maximum current distribution on the surface. Finally the simulated results using Computer Simulation Technology (CST) microwave studio 2009 in this design is compared with manual computation results which are found to be suitable for WLAN applications.
\end{abstract}

Index Terms: Micro-strip antenna; Cavity model; Dual band antenna; Coaxial probe feed.

(C) 2016 Published by MECS Publisher. Selection and/or peer review under responsibility of the Research Association of Modern Education and Computer Science

\section{Introduction}

The importance of electronic circuit miniaturization in wireless communication systems has increased rapidly due to their portability and easy of handling. In last decades the information and communication fields becomes popular because of availability of these tiny sized electronics devices and the capability of

*Corresponding author

E-mail address: dobir.aece@gmail.com 
maintaining high performance. So the investigation on microstrip antenna is become a popular topic for new researchers because of light weight, low cost, planar or conformal layout, and ability of integration with electronic or signal processing circuitry[1]-[2]. Also there is versatility in terms of operating frequency, polarization pattern and impedance in application of microstrip antenna such as in aircraft, missiles (radar, proximity fuses and telemetry), satellite communications, remote sensing and biomedical applicators.

There are several types of microstrip antenna have been introduced and investigated and there observed some operational disadvantages which are narrow frequency bandwidth, larger value of $\mathrm{Q}$, poor polarization purity and low efficiency [3]. But in some applications the microstrip patch antenna is the first choice where narrow frequency bandwidth with lower antenna size are desirable. Besides the use of thick dielectric substrate allow the good efficiency and large frequency band in a microstrip patch antenna [4]-[5]. Recently the coaxial probe feed method with staking and cavity model has become popular, because it reduces the value of surface wave while maintaining the lower size and larger bandwidth of the desired antenna. It has also observed that the use of E-shape slot on the patch reduces the size of the antenna by comparing it without slot [6]-[9]. .

In this research work it is desired to obtain a simple dual band, new single-fed antenna configuration for linear polarization without a polarizer while retaining their lower size, good efficiency and also cost effective. To obtain our desired dual band antenna firstly we have simulated single band microstrip antenna (MSA) also we have studied the effects of physical parameters on output and then it extend to dual band MSA. The simulated results of return loss, smith chart, radiation pattern, directivity, gain, and efficiency of the desired dual band antenna are demonstrated in section 4.

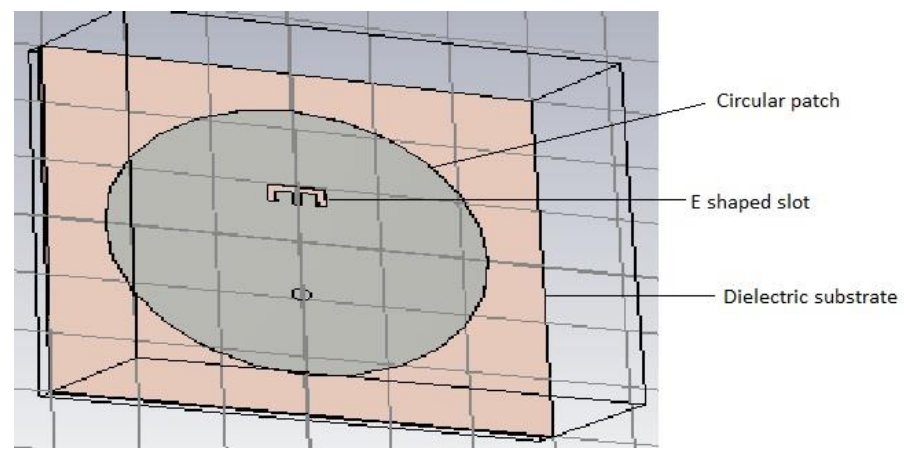

Fig.1. Geometry of dual band microstrip patch antenna

\section{Antenna Configuration}

The desired dual band linear polarized microstrip antenna which resonances at the frequency of $2.76 \mathrm{GHz}$ and $5.9 \mathrm{GHz}$ is shown in fig. 1 . One of the most popular circular patches is designed on the upper layer of substrate. It shows good output characteristics for single element. According to cavity model formulation by assigning some presumed specified information likes the resonant frequency $\left(\mathrm{f}_{\mathrm{r}}\right)$, height of the substrate and the dielectric constant of the substrate $\left(\varepsilon_{\mathrm{r}}\right)$ the equations of our designed antenna are shown in this section [10]. The effective radius of the circular patch at a resonant frequency $\left(f_{r}\right)$ for the dominant mode $\mathrm{TM}_{110}$ with counting fringing can be obtained using equation 1

$$
a_{e f f}=\frac{x_{11}^{\prime} \times C}{2 \pi f_{r} \sqrt{\varepsilon_{r}}}
$$

Here, the lowest order mode $\mathrm{TM}_{110}$, uses $\mathrm{X}_{11}(1.84118)$

Then the actual radius will be 
$a=\frac{a_{e f f}}{\sqrt{\left\{1+\frac{2 h}{\pi \varepsilon_{r} a_{e f f}}\left[\ln \left(\frac{\pi a_{e f f}}{2 h}\right)+1.7726\right]\right\}}}$

\section{Antenna Designed Specifications}

The various parameters of the designed dual band circular microstrip antenna are shown table 1 .

Table 1. The value of different parameters of dual-band rectangular microstrip antenna

\begin{tabular}{ll}
\hline Variable & Value \\
\hline Radius of the patch(a) & $26 \mathrm{~mm}$ \\
Height of the patch(h) & $.07 \mathrm{~mm}$ \\
Effective dielectric constant of the patch $\left(\varepsilon_{\text {eff }}\right)$ & 4.9 \\
Width of small slots(w) & $1 \mathrm{~mm}$ \\
Length of small slots(l) & $2 \mathrm{~mm}$ \\
Width of large slot(W) & $1 \mathrm{~mm}$ \\
Length of large $\operatorname{slot}(\mathrm{L})$ & $7 \mathrm{~mm}$ \\
\hline
\end{tabular}

\section{Simulation Results}

Antennas were designed and tested to verify the circularly polarizing operation of the proposed configuration. The different simulated results (using the CST microwave stdio2009) like return loss, Smith chart, voltage standing wave ratio (VSWR), directivity and gain are discussed below.

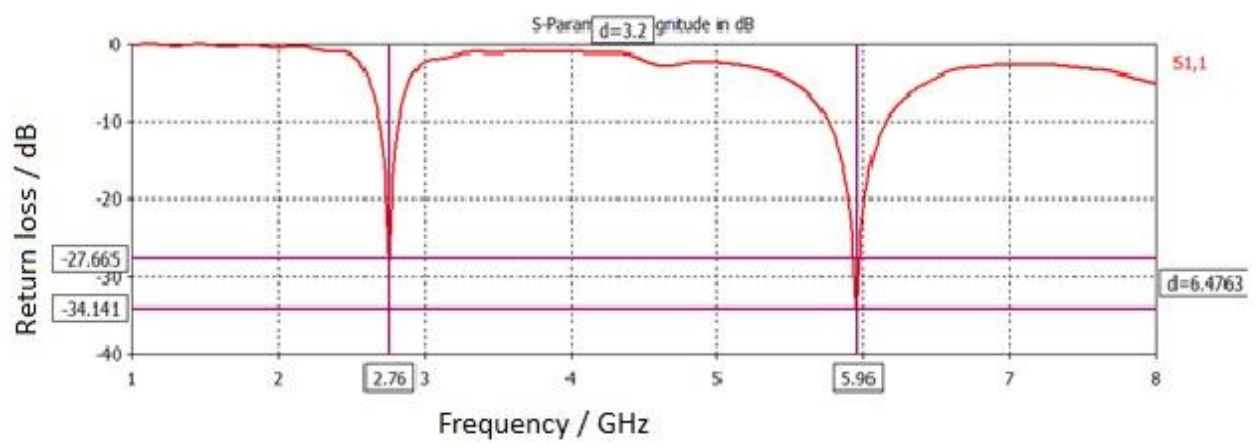

Fig.2. Simulated return losses of dual band MSA at $2.76 \mathrm{GHz}$ and $5.96 \mathrm{GHz}$

\subsection{Return Loss, Smith chart, VSWR}

In antenna the return loss (RL) is a parameter which indicates how the impedance matching has occurred in between transmitter an antenna. For the case of good impedance matching the power losses become minimum and the antenna becomes more efficient. The proper impedance matching is obtained through the proper 
selection of the input feed point. The return loss of the designed dual band microstrip patch antenna is shown in fig.2. It is seen that the return loss, $-27.665 \mathrm{~dB}$ is found at a resonant frequency of $2.76 \mathrm{GHz}$ and that of $34.141 \mathrm{~dB}$ is found at a resonant frequency of $5.96 \mathrm{GHz}$, where $-10 \mathrm{~dB}$ is acceptable for practical applications. The bandwidths are found $120 \mathrm{MHz}$ at the resonant frequency of $2.76 \mathrm{GHz}$ and $200 \mathrm{MHz}$ at the resonant frequency of $5.96 \mathrm{GHz}$, in which $84 \mathrm{MHz}$ is acceptable bandwidth [11].

Fig.3. shows the smith chart which is helpful to calculates the impedance of our designed antenna. The impedance of the designed antenna is founded $45 \mathrm{ohms}$ which is close to acceptable value, $50 \mathrm{ohms}$. The smith chart shows two circles for two resonating frequencies. The circles pass through resistance 1 circle which proves that the antenna is perfectly matched and thus losses are minimum.

The another important parameter for a microstrip antenna to obtain proper impedance matching is VSWR. Fig.4. shows the VSWR curve. It shows that the value of VSWR of our designed antenna is below 2 for the whole bandwidth where for a practical antenna the value of VSWR should be less than or equal to 2 is acceptable. So this parameters indicates that the designed antenna is operable in required frequency band.

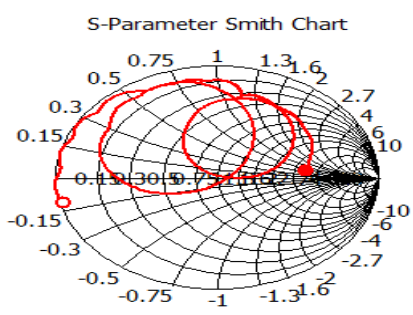

$\mathrm{S1,1}(45 \mathrm{Ohm})$

Fig.3. Smith chart of dual band MSA at $2.76 \mathrm{GHz}$ and $5.96 \mathrm{GHz}$.

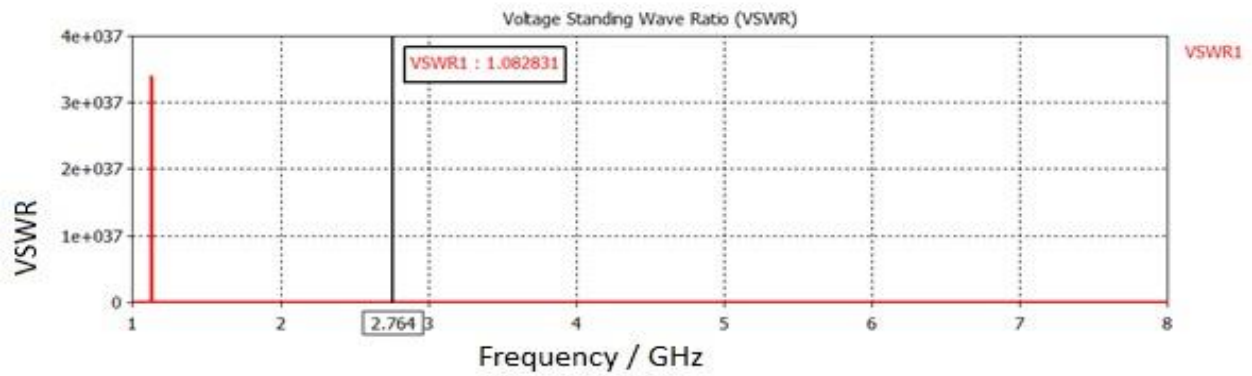

(a)

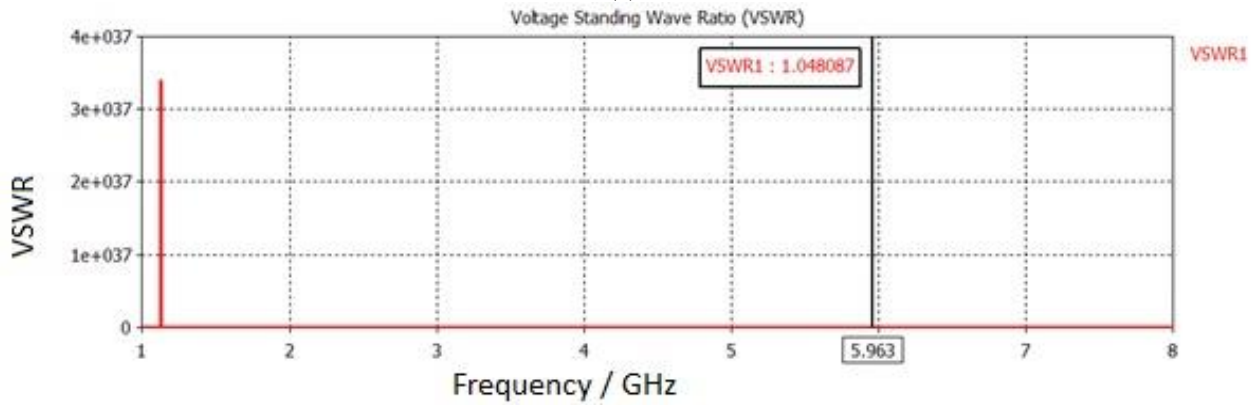

(b)

Fig.4. The VSWR of dual band MSA at (a) $2.76 \mathrm{GHz}$; (b) $5.96 \mathrm{GH}$ 


\subsection{Directivity and Gain}

The directivity of the designed dual band circular microstrip antenna in both 2D and 3D pattern are shown in fig.5. and fig.6. and the gain in fig.7. and fig.8. respectively. From the fig.5. it is clear that the directivity is $9.037 \mathrm{~dB}$ at the resonant frequency of $2.76 \mathrm{GHz}$ and that of $5.96 \mathrm{GHz}$ frequency is $7.992 \mathrm{~dB}$ which agree well with the previous results. From 2D pattern it also clear that the main lobe magnitudes are found at the angle of $3.0 \mathrm{deg}$ and $25.0 \mathrm{deg}$ with positive $\mathrm{Z}$ direction at the resonant frequency of $2.76 \mathrm{GHz}$ and $5.96 \mathrm{GHz}$ respectively. So it proves that the designed dual band antenna is a high directional antenna [11]-[13].

From fig.7. and fig.8. the gains of the dual band antenna are $7.819 \mathrm{~dB}$ and $7.878 \mathrm{~dB}$ found at these two resonance frequencies respectively. Since the designed antenna is a high directional antenna so the gain of the antenna is high at a specific direction. From 2D pattern it is also clear that the main lobe magnitudes of gain are $7.8 \mathrm{~dB}$ and $5.6 \mathrm{~dB}$ are found at the angle of $3.0 \mathrm{deg}$ and $25.0 \mathrm{deg}$ with positive $\mathrm{Z}$ direction at $2.45 \mathrm{GHz}$ and 4.1 $\mathrm{GHz}$ frequencies respectively and these are suitable values for practical applications.
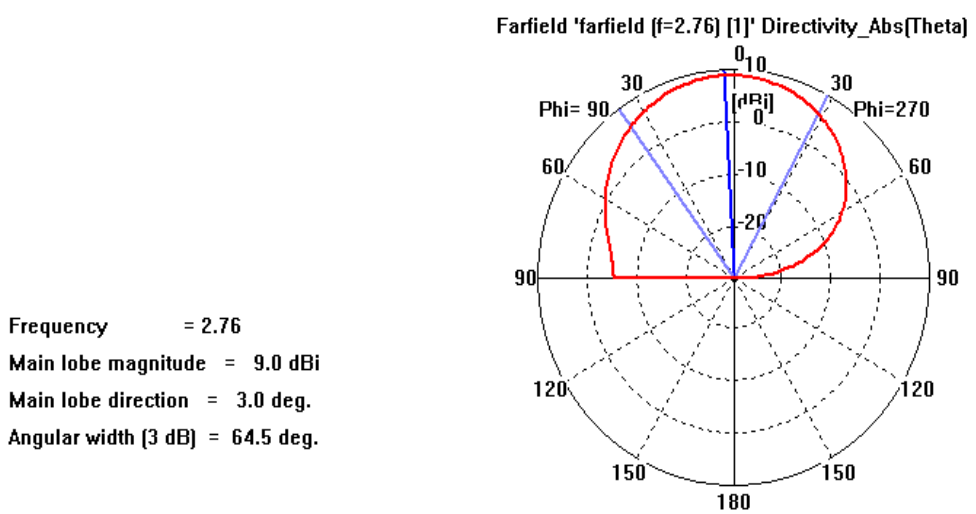

(a)

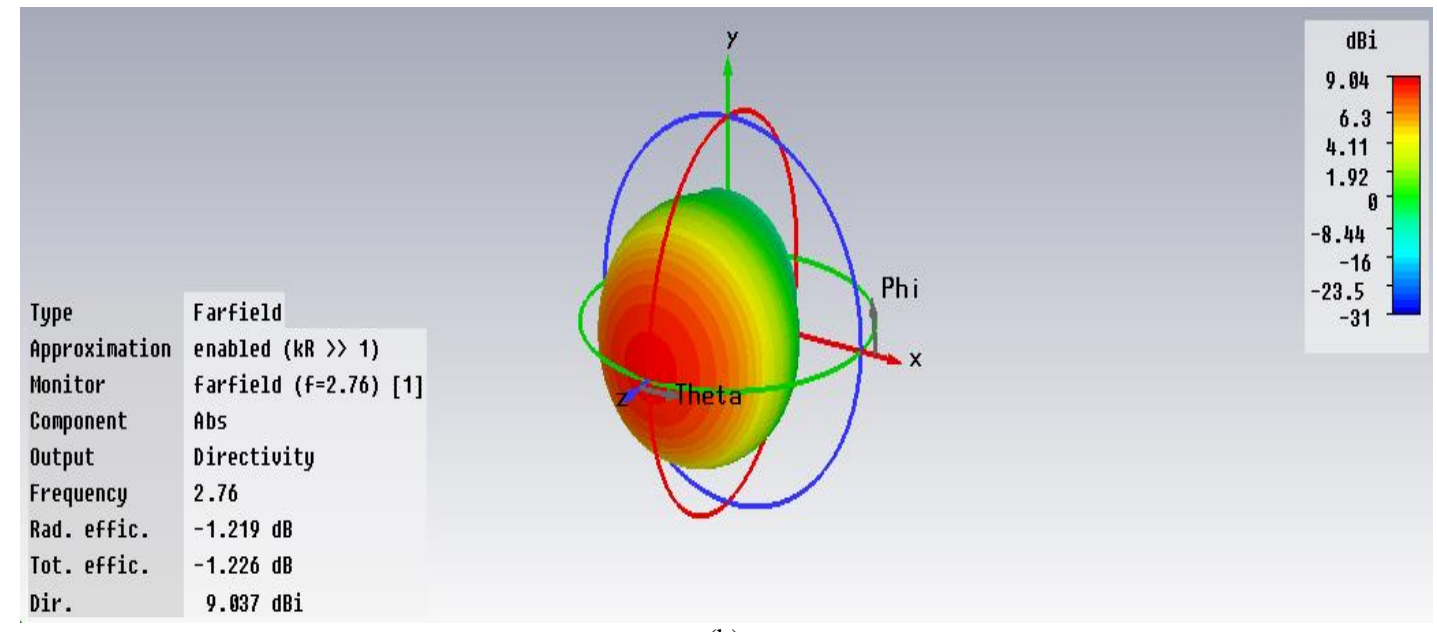

(b)

Fig.5. Directivity of dual band MSA at $2.76 \mathrm{GHz}$ (a) 2D pattern; (b) 3D pattern 


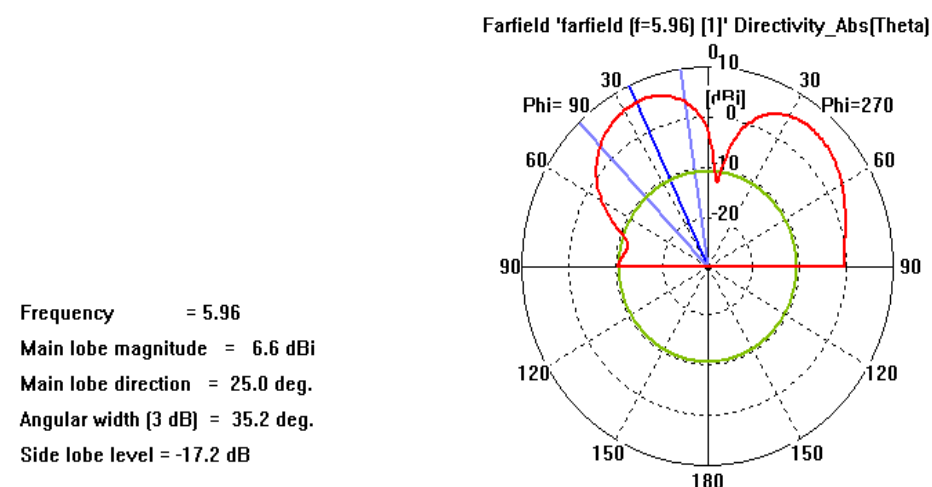

(a)

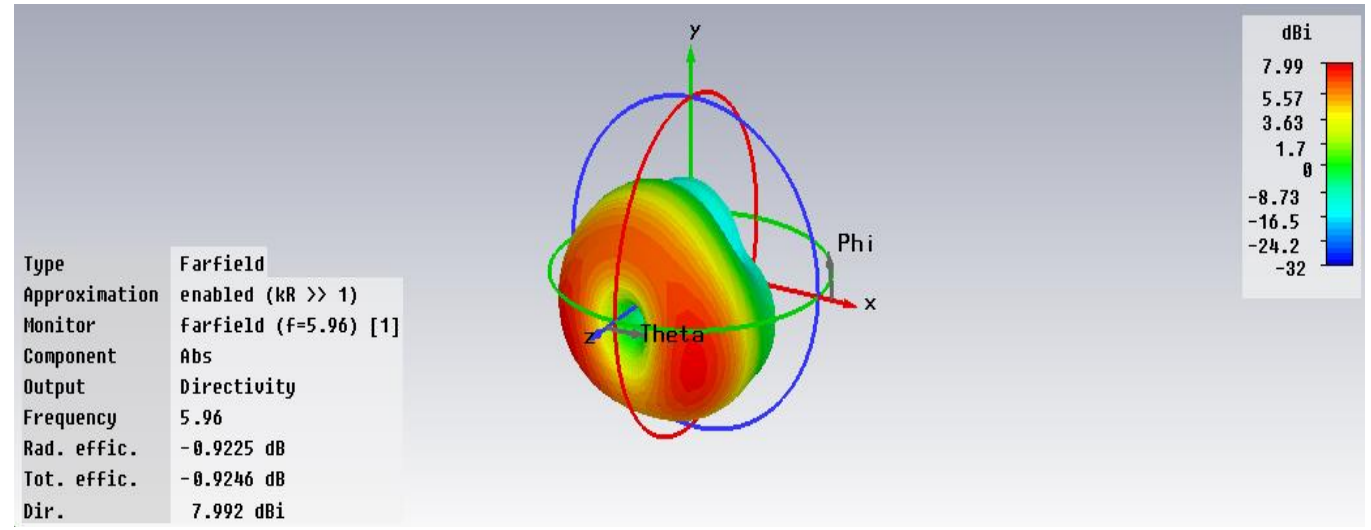

(b)

Fig.6. Directivity of dual band MSA at $5.96 \mathrm{GHz}$ (a) 2D pattern; (b) 3D pattern

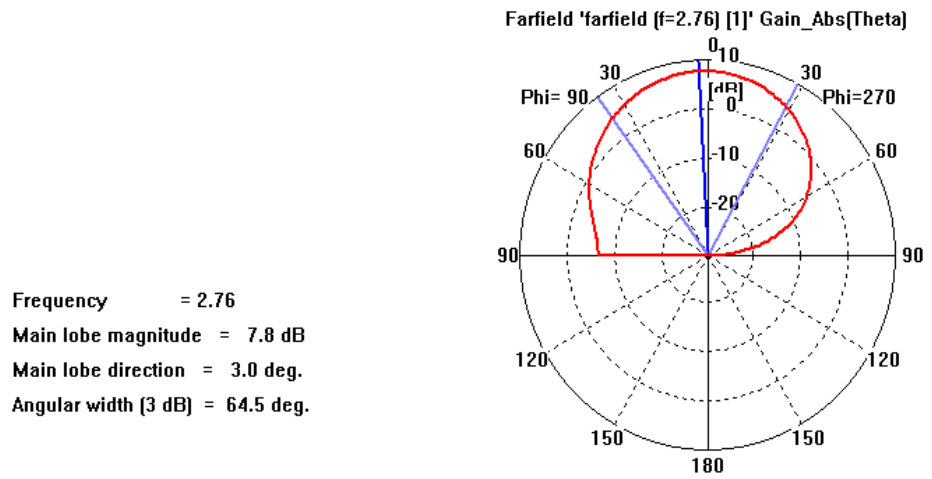

(a) 


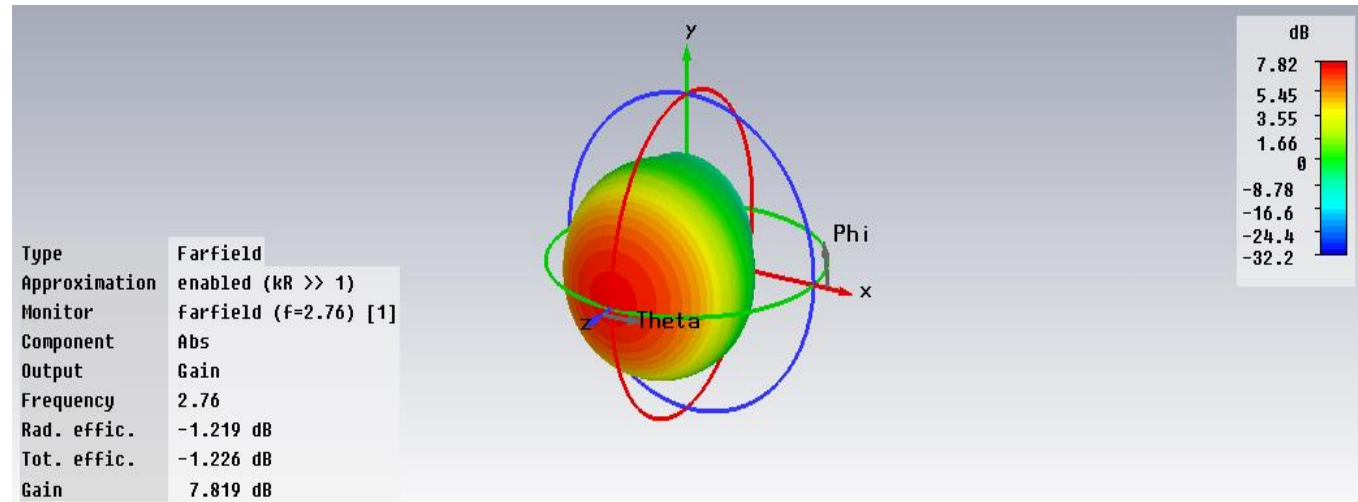

(b)

Fig.7. Gain of dual band MSA at $2.76 \mathrm{GHz}$ (a) 2D pattern; (b) 3D pattern
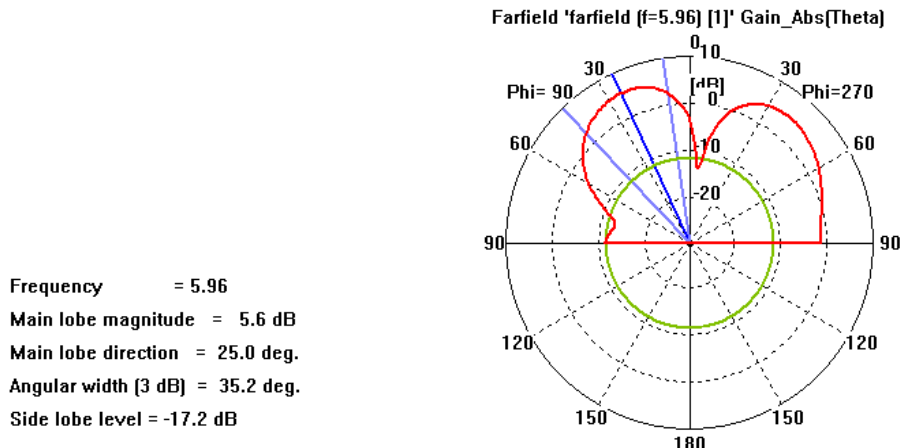

(a)

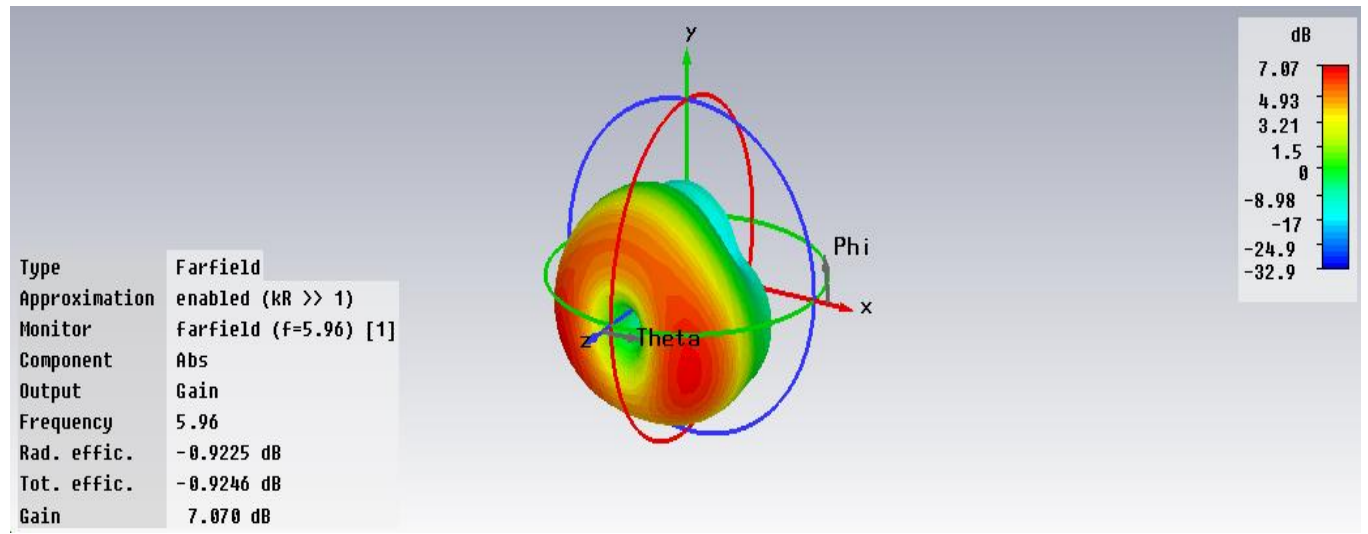

(b)

Fig.8. Gain of dual band MSA at $5.96 \mathrm{GHz}$ (a) 2D pattern; (b) 3D pattern

\section{Summary of the results}

The results of the dual band antenna operating at $2.76 \mathrm{GHz}$ and $5.96 \mathrm{GHz}$ are summarized in table 2 . 
Table 2. Output parameters of the dual band antenna resonating at $2.76 \mathrm{GHz}$ and $5.96 \mathrm{GHz}$ frequencies

\begin{tabular}{llllll}
\hline $\begin{array}{l}\text { Resonating frequency, fr } \\
(\mathrm{GHz})\end{array}$ & Return Loss(dB) & $\begin{array}{l}\text { Bandwidth } \\
(\mathrm{MHz})\end{array}$ & VSWR & $\begin{array}{l}\text { Directivity } \\
(\mathrm{dBi})\end{array}$ & $\begin{array}{l}\text { Gain } \\
(\mathrm{dB})\end{array}$ \\
\hline 2.76 & -27.665 & 120 & 1.08 & 9.037 & 7.819 \\
5.96 & -34.141 & 200 & 1.05 & 7.992 & 7.878 \\
\hline
\end{tabular}

From the above table it is clear that the desired microstrip antenna provides good impedance matching at two resonance frequencies of $2.76 \mathrm{GHz}$ and $5.96 \mathrm{GHz}$ with return losses of $-27.665 \mathrm{~dB}$ and $-34.141 \mathrm{~dB}$ respectively. So it is a dual band antenna with high directivities of $9.037 \mathrm{~dB}$ and $7.992 \mathrm{~dB}$ at these two resonance frequencies respectively. Also the higher value of gains of our designed antenna has achieved because of high directivity of the antenna.

\section{Physical Parametric Study of Dual Band Antenna}

The effect of radius of the circular patch on the performance of the designed microstrip antenna is shown in fig.9. From figure it is seen that with the decreasing value of radius of the radiating patch the resonating frequency increases. At the same time there is changing the return loss with the changing value of radius of the patch. Thus it is a very important tools for determining the actual dimensions of designed circular microstrip patch antenna. Also this study is very helpful to obtain good impedance matching.

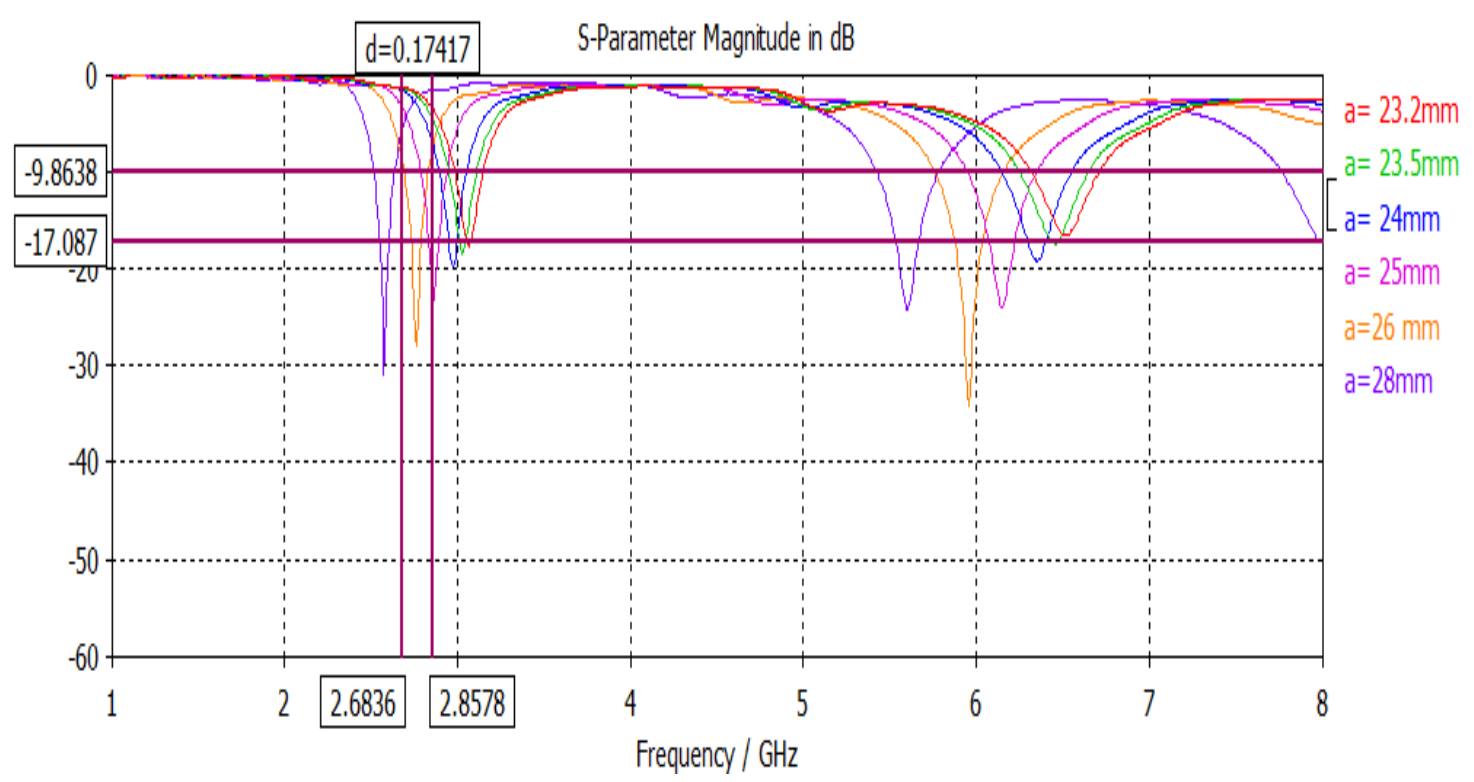

Fig.9. Variations of $\mathrm{S}$ parameter with respect to the radius of the patch

\section{Conclusions}

The work in this research was primarily focused on the design and simulation of simple, small and high efficiency dual band circular microstrip patch antennas using coaxial feeding technique. Then from the 
simulation results the multiband microstrip antenna has designed. The designed rectangular antenna covers two frequencies of $2.76 \mathrm{GHz}$ and $5.96 \mathrm{GHz}$ which produces the bandwidth of approximately $3 \%$ while maintaining their lower size and good efficiency. And also it has shown that the designed antenna provides good impedance matching of approximately $50 \mathrm{ohm}$ 's at resonant frequencies. Due to easy of fabrication with coaxial feeding line it can be used for various applications such as in military purposes, radio altimeters and various wireless devices.

\section{Acknowledgements}

We would like to thank all concerned with the AECE department for their all-out effort to support us for completing this research.

\section{References}

[1] Neha Parmar et al Int. Journal of Engineering Research and Applications ISSN: 2248-9622, Vol. 4, Issue 1(Version 1), pp. 168-171, January 2014.

[2] Neha Parmar et al Int. Journal of Engineering Research and Applications ISSN: 2248-9622, Vol. 4, Issue 1(Version 1), pp. 168-171, January 2014.

[3] Garg, R., Bhartia, P. and Ittipiboon, A., "Microstrip Antenna Design Handbook, Boston Artech, House", 2001.

[4] C. M. Krowne, "Cylindrical-Rectangular Microstrip Antenna", IEEE Trans. Antennas Propagat.,Vol.AP 31, No. 1, pp. 194-199, January 1983.

[5] I. Lier and K. R. Jakobsen, "Rectangular Microstrip Patch Antennas with Infinite and Finite Ground-Plane Dimensions”, IEEE Trans. Antennas Propagat., Vol.AP-31, No. 6, pp. 978-984, November 1983.

[6] S. A. Long and M. D. Walton, "A Dual-Frequency Stacked Circular-Disc Antenna", IEEE Trans. Antennas Propagat., Vol. AP-27, No. 2, pp. 270-273, March 1979.

[7] J. T. Aberle and F. Zavosh, "Analysis of Probe-Fed Circular Microstrip Patches Backed by Circular Cavities", Electromagnetics, Vol. 14, pp. 239-258, 1994.

[8] A. Henderson, J. R. James, and C. M. Hall, "Bandwidth Extension Techniques in Printed Conformal Antennas”, Military Microwaves, Vol. MM-86, pp. 329-334, 1986.

[9] H. F. Pues and A. R. Van de Capelle, "An Impedance Matching Technique for Increasing the Bandwidth of Microstrip Antennas”, IEEE Trans. Antennas Propagat., Vol. AP-37, No. 11, pp. 1345-1354, November 1989.

[10] Constantine A. Balanis, “Antenna Theory - Analysis and Design”, Third Edition.

[11] R.J. Lin, M. Ye, “A Novel Dual-Band Microstrip Antenna for WLAN Application," Wireless Mobile and Computing (CCWMC) IET International Communication Conference, Shanghai, China, pp.269-271, December 2009.

[12] Kuang Fuqiang, Shen Dongya, Xu Jie, Shuai Xinfang, Ren Wenping, “A triple-band Microstrip Antenna for WLAN Applications," International Conference on Communications and Mobile Computing, Shenzhen , pp. 68-71, 2010.

[13] Amit A. Deshmukh, M. Parulekar, S. Kadam and Ameya Kadam, "Broadband Proximity Fed Modified E -Shaped Microstrip Antenna," National Conference on Communications (NCC), Bangalore, pp.1-5, 2011. 


\section{Authors' Profiles}

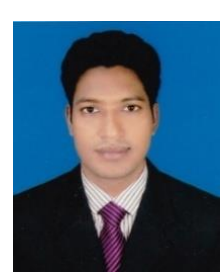

Mr. Sheikh Dobir Hossain is working as a Lecturer in the dept. of Physics at Jessore University of Science and Technology, Jessore-7408, Bangladesh. He holds the degree of B.Sc \& M.Sc in Applied Physics, Electronics \& Communication Engineering from Islamic University, Kushtia-7003, Bangladesh. The fields of his research interest are wireless antenna design, wireless communication, and material science.

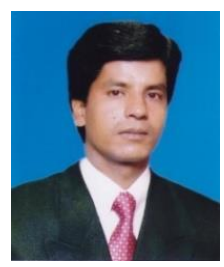

Mr. K. M. Abdus Sobahan received his PhD degree from the Inha University, South Korea. $\mathrm{He}$ received his Bachelor's and Master's degree from the dept. of Applied Physics \& ElectronicsUniversity of Rajshahi, Rajshahi-6205, Bangladesh. Currently he is working as a professor in the dept. of Applied Physics, Electronics \& Communication Engineering of Islamic University, Kushtia-7003, Bangladesh.

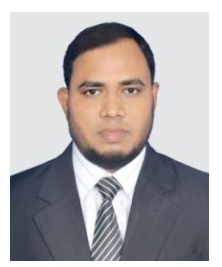

Mr. Md. Khalid Hossain has received the B.Sc (Hons) and M.Sc degree in Applied Physics, Electronics \& Communication Engineering of Islamic University, Kushtia-7003. Currently he is working as a Scientific Officer in the Institute of Electronics, AERE, Bangladesh Atomic Energy Commission, Savar, Dhaka-1349, Bangladesh. His current interest are material science, nano-materials, dye-sensitized solar cell (DSSC), micro \& nanofabrication, biosensor, RF MEMS, wireless antenna design. His work has produced 06 peer-reviewed scientific international journal papers.

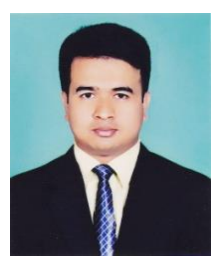

Mr. Mr. Md. Khalid Hossain Jewel received his Bachelor's and Master's degree from the dept. of Applied Physics, Electronics \& Communication Engineering of Islamic University, Kushtia-7003, Bangladesh in 2004 and 2005 respectively. Currently he is working as an assistant professor in the same department .His research interest includes Ad-hoc wireless communication, cellular mobile communication and optical fiber communication.

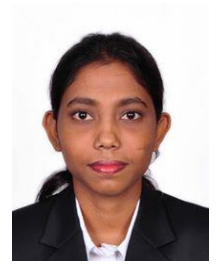

Ms. Rebeka Sultana has been received B.Sc (Eng.) degree in Computer Science \& Engineering (CSE) from University of Rajshahi, Rajshahi-6205, Bangladesh. Currently she is a MS student of the Department of Electrical \& Electronic Engineering (EEE), Shizuoka University, Japan. Her current research interest are computer vision, pattern recognition, image processing, artificial intelligence, signal processing, digital image processing, automatic control, wireless antenna design and wireless communication. 


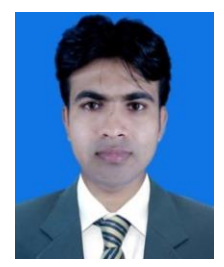

Mr. Md. Al Amin has completed B.Sc and M.Sc in Computer Science and Engineering from Islamic University, Kushtia, Bangaldesh. Currently he is working as a lecturer, Dept. of CSE at Jessore University of Science and Technology, Jessore-7408, Bangladesh. His research interest fields are Next generation Wireless Communication, Wireless Antenna Design, Information Security and Network Security.

How to cite this paper: Sheikh Dobir Hossain, K. M. Abdus Sobahan, Md. Khalid Hossain, Md. Khalid Hossain Jewel, Rebeka Sultana, Md. Al Amin,"A Linear Polarized Coaxial Feeding Dual Band Circular Microstrip Patch Antenna for WLAN Applications",International Journal of Wireless and Microwave Technologies(IJWMT), Vol.6, No.3, pp.50-60, 2016.DOI: 10.5815/ijwmt.2016.03.06 